BULLETIN Bulletin hispanique

HISPANIQUE Université Michel de Montaigne Bordeaux

110-1 | 2008

Varia

\title{
La histeria de Paulina Porreño en La Fontana de oro de Galdós
}

Bienvenido Morros Mestres

\section{(2) OpenEdition}

1 Journals

Edición electrónica

URL: https://journals.openedition.org/bulletinhispanique/664

DOI: 10.4000/bulletinhispanique.664

ISSN: 1775-3821

Editor

Presses universitaires de Bordeaux

Edición impresa

Fecha de publicación: 1 junio 2008

Paginación: 333-370

ISBN: 978-2-86781-511-9

ISSN: 0007-4640

Referencia electrónica

Bienvenido Morros Mestres, «La histeria de Paulina Porreño en La Fontana de oro de Galdós», Bulletin hispanique [En línea], 110-1 | 2008, Publicado el 01 junio 2011, consultado el 18 septiembre 2021. URL: http://journals.openedition.org/bulletinhispanique/664 ; DOI: https://doi.org/10.4000/ bulletinhispanique.664

Tous droits réservés 


\title{
La histeria de Paulina Porreño en La Fontana de oro de Galdós
}

\author{
Bienvenido Morros Mestres \\ Universidad Autónoma de Barcelona - España
}

L'attention se porte, dans cette étude, sur la maladie dont souffre l'héroïne de La Fontana de Oro de Galdós, maladie conçue comme un clair euphémisme de l'hystérie. Pour parvenir à cette conclusion, est d'abord évoquée la relation avec Sainte Thérèse, dont les problèmes de santé, très semblables à ceux du personnage de Galdós, avaient été interprétés comme d'évidents symptômes d'hystérie par les médecins français du début du XIX siècle. Des textes de médecine française - générale ou spécialisée en neurologie - permettent de mettre en relation les deux maladies, l'hystérie et la catalepsie, quion pensait liées au fanatisme religieux de ceux qui en étaient atteints. Enfin, l'analyse d'autres personnages de la litterature française, en particulier Madame Gervaisais, des frères Goncourt, montre quils sont tous taillés sur le modèle du mysticisme et de la catalepsie.

En ese trabajo se llama la atención sobre la enfermedad que padece la protagonista de La Fontana de oro de Galdós para considerarla un claro enfemismo de la histeria. Para llegar a semejante conclusión se analiza primero su relación con santa Teresa de Jesús, cuyos problemas de salud, muy similares a los del personaje de Galdós, se habian interpretado como claros sintomas de la histeria en la medicina francesa de principios del siglo XIX. Después se aducen los textos de medicina francesa, tanto la general como en la especialidad de neurología, en que se relacionan las dos enfermedades por creerlas favorecidas por el fanatismo religioso de quienes puedan sufrirlas. Por último, se analizan otros personajes de la literatura francesa, especialmente Madame Gervaisais de los hermanos Goncourt, para suponerlos todos cortados por el mismo patrón del misticismo $y$ la catalepsia.

$B H i$, Tome 110, nº 1 - juin 2008 - p. 333 à 370. 
This work focuses on the illness of the heroine of La Fontana de oro by Galdos, clearly seen as a euphemism for hysteria. In order to reach this conclusion, the relationship between Paulina and Santa Teresa de Jesus is first analyzed: her health problems were very similar, and they were understood as clear symptoms of hysteria by French doctors in the early XXth century. French medical texts (general or specialized in neurology) provide a link between hysteria and catalepsy, which were previously thought to be caused by religious fanaticism. Finally, some other characters of French literature are also analysed, especially Madame Gervaisais, by the Goncourt brothers, who also follow that same pattern of mysticism and catalepsy.

Mots-clés : XIX ${ }^{\mathrm{e}}$ siècle - Littérature française - Littérature espagnole - Dictionnaires de médecine - Neurologie - Psychiatrie - Sainte Thérèse d'Avila - Éditions Sainte Thérèse XIX ${ }^{\mathrm{e}}$ - Mysticisme - Catalepsie - Hystérie.

$\mathrm{E}$ $\mathrm{N}$ los últimos años la crítica, especialmente la francesa, ha estudiado las fuentes médicas usadas por Clarín en La Regenta, obras todas, también escritas en francés, sobre enfermedades del sistema nervioso contemporáneas al novelista ovetense. Esa misma crítica ha relacionado, de manera muy acertada, el personaje de Ana Ozores con el histórico de Santa Teresa, de quien en 1882 se celebraba el tercer aniversario de su muerte y a quien solía mencionarse, junto a otras santas, en los tratados sobre la histeria y enfermedades afines ${ }^{1}$.

1. Son ejemplares, en ese sentido, los trabajos de Simone Saillard, «Louvain, Salamanque, Lyon, Roma. Itinéraire européen d'une controverse à propos de Sainte-Thérèse, 1882», en Les Catholiques libéraux au XIX siècle, Grenoble, PUG, 1974; "La peritonitis de don Víctor y la fiebre histérica de Ana Ozores : dos calas en la documentación médica de Leopoldo Alas novelista ", en Realismo y naturalismo en España en la Segunda mitad del siglo XIX, ed. Yvan Lissorgues, Anthropos, Barcelona, 1988, pp. 315-327; y «Ana Ozores, de la mystique à l'hystérie», Co-textes, 18 (1989), pp. 65-131. También pueden verse Bridget Aldaraca, «El caso de Ana Ozores; histeria y sexualidad en La Regenta», Asclepio, 42 (1990), pp. 51-62, y, más recientemente, Joan Ramon Resina, «Ana Ozores's nerves», Hispanic Review, 71 (2003), pp. 229-252. Un tipo de labor muy similar se ha aplicado a la obra de Emilia Pardo Bazán por Asunción Doménech Montagut, Medicina y enfermedad en las novelas de Emilia Pardo Bazán, UNED, Valencia, 2000, pp. 188-199, y Género y enfermedad mental. Trastornos psíquicos en las novelas de Emilia Pardo Bazán, Universidad de Córdoba, Córdoba, 2000, pp. 61-103. Ya antes se había intentado algo parecido con la novela francesa y anglosajona de la misma época: así, Evelyne Ender, Sexing the mind. Nineteenth-Century Fictions of Hysteria, Ithaca, Cornell University Press, 1995; y Cristina Mazzoni, Saint Hysteria. Neurosis, Mysticism and Gender in European Culture, Cornell University Press, Nueva York, 1996. 
Por lo que respecta a Galdós no se han publicado demasiados estudios sobre las enfermedades mentales de sus protagonistas, pero Leota W. Elliot y F. M. Kerkeville ya lo presentaron como un autor "generally far in advance of his time in his psychological conception of mental disease», después de considerar las posibles influencias de las ideas de Freud en toda su obra, tanto novela como teatro ${ }^{2}$. En un trabajo importante, una especialista en el tema de la histeria en la literatura española del siglo XIX, Bridget A. Aldaraca, analizó a los personajes femeninos de media docena de novelas de Galdós, desde La familia de León Roch a Tristana, pero siempre en su papel de esposas y ángeles del hogar, y muy esporádicamente prestando atención a su sexualidad ${ }^{3}$.

Yo, por mi parte, me voy a centrar en su primera novela, que estudiaré desde la doble perspectiva neurológica y literaria, teniendo en cuenta los tratados y novelas que nuestro narrador pudo llegar a leer para crear a sus personajes femeninos y atribuirles sus problemas de salud. En ese período inicial de su producción no ofrece demasiadas pistas sobre sus posibles fuentes ${ }^{4}$, pero la medicina y la literatura contemporáneas, mayormente la francesa, pudieron ofrecerle la información necesaria para plantear una serie de cuestiones que debieron de tener bastante repercusión en la sociedad

2. En «Galdós and Abnormal Psychology», Hispania, 23 (1940), p. 27. Otros críticos han seguido el mismo tipo de análisis y lo han aplicado a una de sus novelas más conocidas, Fortunata y Jacinta, como, por ejemplo, George H. Allison, «Les perspectives psychanalytiques intuitives de Galdós dans Fortunata y Jacinta», International Journal of Psycho-Analyse, et le Bulletin de l'International Psycho-Analytical Association, LV (1974), pp. 333-343. También ha estudiado el tema de la histeria en el protagonista masculino de La incógnita Mark Harpring, «Gossiping and Hysterical Manolo Infante: traditionnal gender role crossing as political metaphor in Galdós's La incógnita», Hispania, 90 (2007), pp. 1-9.

3. El libro se titula El ángel del hogar: Galdós y la ideología de la domesticidad en España, Visor, Madrid, 1992.

4. En cambio, dentro de su obra más tardía, sí menciona a autoridades sobre la materia. Así, por ejemplo, en la serie de novelas dedicadas al personaje de Francisco de Torquemada, que se empezaron a publicar en 1889, saca a relucir diferentes especialistas sobre tema médico. Así, en Torquemada en el Purgatorio, cuando la familia Águila ya se había instalado en casa del usurero, el menor de los tres hermanos, don Rafael, da muestra de ciertos desórdenes cerebrales, y sus hermanas, Cruz y Fidela, se plantean llevarlo a París para que lo visite Charcot, a quien Fidela presenta como «el primer sabio de Europa en enfermedades cerebrales» (286). Un poco después, al entrar en acción, Zárate, el amigo pedante de la familia, habla de los padres del hipnotismo, el escocés James Braid y el francés Ambroise-Auguste Liébault, y del primero llega a citar su gran obra, Neurhypnology or the rationale of nervous sleep considered in relation with animal magnetism (Londres, 1843). El segundo fue el fundador en 1866 de la escuela de Nancy, que se opuso a la de la Salpêtrière, creada por Charcot, sobre todo porque concebía la histeria como una enfermedad exclusivamente psicológica. 
decimonónica en la que vivió, sobre todo en los ambientes más cultos a los que no fue ajeno. Sus primeros personajes no tienen la profundidad psicológica (son bastante planos en ese sentido) de los personajes literarios en que pudo inspirarse (sobre todo, la de Madame Gervaisais, Marthe Rougon o Madame Bovary), pero corresponden ya a prototipos que ilustran sus ideas sobre los temas, especialmente de sexualidad y religión, que decide plantear a través de ellos.

\section{LA FONTANA DE ORO}

La primera gran novela de Galdós, teñida aún de costumbrismo e historicismo, es La Fontana de oro, que comienza a escribir poco antes de la Revolución del 68 y termina dos años después, a finales de 1870. El novelista canario mezcla unos cuantos personajes históricos (Galiano, Morillo y Fernando VII) con otros muchos ficticios. Entre estos últimos llama la atención el trío formado por las señoras Porreño, la tía y sus dos sobrinas, de hermanos distintos. Dońa María de la Paz, la tía, ha sobrepasado en el momento de la acción los cincuenta años, y doña Salomé, la sobrina mayor, ya ha cumplido los cuarenta. La sobrina pequeña se acerca a la edad de Cristo, pues ha alcanzado los treinta y dos años. Ninguna de las tres ha tenido una vida demasiado envidiable.

La mayor, doña María de la Paz, cuando se hallaba en edad núbil, a los diecinueve ańos, estuvo a punto de casarse dos veces, primero con un joven de la casa de Gaytán de Ayala, después, a los cuatro meses, con un caballero irlandés que estaba en la Embajada inglesa. No se casó con ninguno de los dos, o bien porque ella no quiso, o bien porque al final no contó con la aprobación del marqués, y por eso hubo de contentarse, al cabo de cinco años, cuando rondaba los veinticuatro, con un marido viejo, «que cometió el singular despropósito de morirse a los siete días de casarse " 5 .

Doña Salomé galanteó con un joven duque, con quien incluso proyectó contraer matrimonio, pero los padres del muchacho, seguramente enterados de la ruina de la familia de los Porreño, impidieron que su hijo se casara con la hija del marqués, quien, a causa del disgusto, «estuvo siete días en cama con dolor de muelas» (148). Antes de ese proyecto frustrado de boda, doña Salomé se había enamorado de un teniente de Húsares del Rey, por quien

5. Siempre cito por el texto reproducido por Alianza Editorial, Madrid, 1991, p. 147. A partir de este momento los números entre paréntesis, después de una cita, remiten a esta edición. 
se pasaba las noches llorando. El marqués no debió ver con buenos ojos ese noviazgo, porque el teniente fue mandado al Perú y ya no se supo nada más de él. La muchacha desde entonces había desarrollado fuertes ataques nerviosos y forjado un carácter bastante misantrópico.

Dońa Paulina, la más joven, siempre había hallado consuelo en la religión, y a los dieciocho años, cuando su tío el marqués le propuso casarse, decidió o ser hija de Jesucristo o vivir en su casa «ausente del mundo, buscando en ella un baluarte contra el demonio» (150). Optó por la segunda solución, y así fue en aumento su devoción, nada hipócrita, hasta el punto de disciplinarse durante la Cuaresma (los criados oían de madrugada los azotes que se daba) y de ser objeto de grandes visiones y arrebatos de amor divino, que solía consultar con unas monjas vecinas de la calle Góngora. A ellas, además, confesaba las «terribles tentaciones» que solían abrumarla y que vencía «bebiendo vinagre» (150). Y es que el cuerpo de la muchacha, a pesar de todo, parecía protestar, con un "hábito de contracciones y movimientos», por el tipo de vida que su alma quería imponerle ${ }^{6}$.

\section{PAULINA Y SANTA TERESA}

Doña Paulina demuestra un gran interés desde su entrada en casa por el sobrino de don Elías, el joven Lázaro, y al día siguiente de esa entrada interroga a Clara sobre el muchacho, mientras intenta abrir un volumen de las obras de San Juan Crisóstomo: al no tener la concentración necesaria para abordar la lectura de un texto de tal envergadura, deja el libro para tomar otro, que era de Santa Teresa, y parece que lo abre, aunque no lo dice el narrador, por Camino de perfección, a quien la abulense también alguna vez denomina Paternóster ${ }^{7}$. Seguramente por ese motivo doña Paulina se equivoca, cuando lo que pretendía en realidad era rezar el padrenuestro y no leer el capítulo 7 de ese libro de Santa Teresa:

Pero en vez de pronunciar el Pater noster fundamental, que es lo que procedía para empezar de nuevo, clavó los ojos en el libro y maquinalmente leyó:

6. Un análisis del personaje, aunque del todo insuficiente, entre otras cosas, porque emplea fuentes medievales, y no decimonónicas, ofrece Jordi Pardo Pastor, «El 'Bovarysmo' en la novela decimonónica», Cuadernos de Investigación Filológica, XXVI (2000), especialmente p. 303.

7. Véase Efrén de la Madre de Dios y Otger Steggink, eds., Santa Teresa de Jesús, Obras completas, Biblioteca de Autores Cristianos, Madrid, 1982, p. 194. 
- «De dos maneras de amor quiero yo agora tratar: uno es [puro] espiritual, porque ninguna cosa parece le toca la sensualidad ni la ternura de nuestra naturaleza; otro es espiritual, y que junta con él nuestra sensualidad y flaqueza...» $(213)^{8}$.

La menor de las Porreño posiblemente manejó la edición de Vicente de la Fuente, un libro en dos volúmenes con el título de Escritos de Santa Teresa y publicados respectivamente en 1861 y 1862 . La edición reproducía la primera de las dos redacciones de la obra, la dividida en setenta y tres capítulos y conservada en un manuscrito de El Escorial ${ }^{9}$. Doña Paulina, sin embargo, tras leer ese pasaje, aparta el libro con desdén y, mirando el techo, se está quieta un buen rato, «sin dar señales de vivir en este mundo» (213), y, cuando vuelve en sí, llamada por Clara, reza el rosario no para reprender duramente, como siempre hacía, a su discípula, sino para dedicarle una sonrisa. Tras sonrojarse por tal motivo, toma otra vez el libro de la santa abulense, y buscando entre sus páginas un pasaje sobre la penitencia lee otras sobre su comentario al Cantar de los cantares titulado, en la edición príncipe del padre Gracián (Bruselas, 1611), y en la de Vicente de la Fuente, Conceptos del amor de Dios. Doña Paulina recita primero los versículos del texto bíblico $(2,6)$ para luego seguir con la explicación de santa Teresa:

\section{Hojeó el libro, y leyó:}

«Sostenedme con flores y acompańadme con manzanas, porque desfallezco de mal de amores». "¡Oh, qué lenguaje tan divino es éste para mi propósito! ¿Cómo, esposa santa, mátaos la suavidad? Porque, según he sabido algunas veces, es tan excesiva, que deshace el alma de manera que no parece que la hay para vivir y pedir flores» $(214)^{10}$.

Al no encontrar el pasaje que buscaba vuelve a hojear el volumen para abrirlo por unas páginas del Libro de la vida, concretamente del capítulo XV sobre el modo de conseguir, a través de la oración, un estado próximo a la unión con Dios:

8. En la edición de Vicente de la Fuente, que citamos a continuación, el pasaje aparece reproducido en la p. 324b, con la variante, consignada en la cita, al poner entre paréntesis cuadrados la palabra "puro" que olvida Galdós.

9. Se publicó en la Biblioteca de Autores Españoles, tomos 53 y 54. Empleo la reimpresión hecha por Atlas en 1952.

10. En la edición de Vicente de la Fuente, tomo 53, p. 403, se lee "pedís flores», y no "pedir flores». 
No, no es esto; a ver esto otro -dijo hojeando más-. «Es, pues, esta oración una centellita que comienza el señor a encender el alma del verdadero amor suyo, y quiere que el alma vaya entendiendo qué cosa es este amor con regalo» $(214)^{11}$.

Tampoco es ése el pasaje que la Porreño pretendía leer, y por eso abandona la búsqueda para entregarse frenéticamente a la oración. Al terminar esa actividad, llevada a cabo en la compañía de Clara, al sentirse sin aliento, tiene necesidad de abrir el balcón para respirar el aire puro. Nunca antes había obrado así, porque nunca antes había experimentado un ahogo como el de ese momento, del día siguiente a la llegada de Lázaro en su casa. Como señala el narrador, doña Paulina padece «una crisis trascendental», operada tanto en su espíritu como en su organismo, y esa crisis aún no deja adivinar qué es lo que le está pasando. Por lo pronto, ha renunciado a la lectura de las obras teológicas de san Juan Crisóstomo y ha buscado consuelo en las de santa Teresa, leyendo las páginas en que la abulense habla del amor divino para explicar el humano que está naciendo en ella. De hecho, la menor de las Porreño ha leído la distinción que hace la santa entre dos tipos de amor espiritual, uno puro y otro contaminado del amor sensual, y sin duda se identificaría con el segundo, porque hasta entonces sólo habría experimentado el primero.

La medicina francesa del siglo XIX, especialmente la frenológica, había dedicado obras enteras a la histeria, convencida de que podía ser esta una enfermedad más neurológica que ginecológica, y de que estaba favorecida por el fanatismo religioso. Para ilustrar semejante idea solía citar una lista de santas y místicas a las que creía víctimas de la histeria. Así, por ejemplo, Paul Briquet, en su Traité clinique et thérapeutique de l'hystérie, publicado en 1859 en París, consagra un capítulo a los "attaques d'extase», donde explica primero en qué consisten para luego, como una manifestación de la histeria, considerarlos propios de personas del sexo femenino que han dejado «une réputation de sainteté ou de béatitude»:

Telles étaient sainte Elisabeth de Hongrie en 1207, sainte Gertrude, sainte Brigitte, sainte Catherine de Sienne en 1347, Jeanne d'Arc, sainte Thérèse, madame de Chantal en 1572, Marie d'Agueda en 1680, madame Guyon, la correspondante de Fénelon, Marie Alacoque, la mère Bellou, mademoiselle Cadière, etc, etc. ${ }^{12}$.

11. En la edición citada, el pasaje aparece en la p. 53b.

12. Cito por la edición original, reproducida en facsímil por Gallica. 
Veinticuatro años después otro neurólogo francés, Legrand du Saulle, en Les hystériques, état physique et état mental (París, 1883), en el capítulo de los "Troubles intellectuels», vuelve a incluir a santa Teresa entre las santas que padecieron la histeria. La lista es prácticamente la misma que la de Briquet, y en ella sólo se aprecian cambios por el final, en que se han suprimido unos cuantos nombres:

Bien des Saintes et des Bienhereuses n'étaient autre chose que de simples hystériques! Qu'on relise les détails de la vie d'Elisabeth, de Hongrie, en 1207, de sainte Gertrude, de sainte Brigitte, de sainte Catherine de Sienne en 1347, de Jeanne d'Arc, de sainte Thérèse, de madame de Chantal, en 1572, de la célèbre Alacoque et de tant d'autres ${ }^{13}$.

Poco antes de morir, en 1893, un neurólogo del hospital de mujeres de la Salpêtrière, el más conocido en la época, Jean-Martin Charcot, en un breve trabajo titulado La foi qui guérit, llega a la conclusión de que san Francisco de Asis y santa Teresa fueron "eux-mêmes hystériques indéniables» ${ }^{14}$, y sólo dos años después, un discípulo suyo, Sigmund Freud, en colaboración con Joseph Breuer, en sus Studies uber Hysterie, de los que sacaron una primera versión en 1893, mencionan a la santa de Ávila como "patron saint of hysterics» ${ }^{15}$.

Fuera de este tipo de obra tan especializada, también en los grandes diccionarios de medicina hallamos el mismo diagnóstico de los problemas de salud de la abulense. Sin ir más lejos, en el Dictionnaire des sciences médicales, en el volumen veintitrés, publicado en París, 1818, entre las muchas páginas dedicadas a la histeria, se habla de la peligrosidad de la memoria e imaginación en las jóvenes vírgenes para acabar mencionando el caso de nuestra santa:

\section{Telle était sainte Thérèse, qui nous représente un exemple d'hystérie mélancolique ${ }^{16}$.}

13. Cito también por la edición original, p. 224. El pasaje aparece citado por Simone Saillard, «Ana Ozores, de la mystique à l'hystérie», p. 127, n. 113, quien añade el testimonio de la Vie de Jesús (París, 1863) de Ernest Renan, al citar un pasaje del último capítulo de esa obra («Caractère essentiel de l'œuvre de Jésus»): «Qui de nous, pygmées que nous sommes, pourrait faire ce qu'a fair l'extravagant François d'Assise, l'hystérique Ste Thérèse ? " (97).

14. Cito por la edición parisina de 1897, p. 10.

15. Para este último dato, véase Cristina Mazzoni, Neurosis, Mysticism, Saint and Gender in Hysteria European Culture, Cornell University, New York, 1996, p. 43.

16. Dictionnaire des sciences médicales par une société de médecins et de chirurgiens, dirigido 
Sin entrar en más detalles sobre el asunto, parece fácil inferir que santa Teresa fue considerada, ya desde 1818, mucho antes de la celebración del tercer centenario de su muerte, una histérica, y que ese diagnóstico tuvo una gran trascendencia en la cultura de la época, incluida la española, que no estaba tanto por la labor de reconocer en una de sus místicas más importantes problemas de salud mental de esa índole.

Fuera como fuere, el caso es que Galdós elige para representar la España más rancia de su época a un personaje a quien atribuye un misticismo precisamente inspirado en la santa abulense, y al obrar de esa manera parece querer poner de manifiesto los males que puede provocar el fanatismo religioso, unos males que relaciona con el tipo de vida que desde su infancia había llevado el personaje en cuestión.

Galdós, en cualquier caso, evita en todo momento calificar a dońa Paulina de histérica, y a cambio prefiere presentar sus problemas de salud con otros nombres menos comprometedores que en última instancia se acababan asociando con la histeria. Ya hacia el final de la novela, al confiarle a Clara los últimos comportamientos de la más joven de las Porreño, Lázaro explica en términos muy clarividentes cuál es la enfermedad que padece la mujer y qué se la provocaba:

Hay una enfermedad... que llaman la catalepsia, y consiste en un paroxismo, durante el cual la persona pierde el movimiento y el habla, quedándose como muerta. Dicen que una de las causas que motivan esta enfermedad es el misticismo religioso y el hábito de los éxtasis y visiones (386).

Un poco antes, al enterarse de que dońa Paulina estaba enamorada de Lázaro, Clara confiesa que ya "lo sabía», y basa ese conocimiento, no en algo que la propia interesada le puede haber dicho, sino en su actitud, especialmente cuando rezaba:

¡Si vieras qué miedo me daba cuando se ponía a orar, quedándose mucho tiempo quieta e insensible, como si estuviera muerta! Se ponía de rodillas, miraba el techo, y así se estaba dos o tres horas sin moverse, y hasta parecía que no respiraba. La tocaba yo, y nada; la llamaba, y no respondía. Por fin, después de mucho tiempo, daba un suspiro y volvía en sí (386).

por Adelon, Alart y Alibert, París, 1812-1822, p. 235. 
Queda más o menos claro que la sobrina más santa de María de la Paz podía sufrir esos estados de semi-coma tras la llegada de Lázaro a su casa, y no antes, porque Clara relaciona semejantes estados con el amor que la dama cree sentir hacia su novio. En la última página de la novela, al no ser correspondida por el sobrino del Coletilla, doña Paulina ingresa en un monasterio, donde sufre nuevos ataques de catalepsia, por lo que están a punto de enterrarla viva:

Poco después de las últimas escenas de esta historia se retiró a un convento, y allí tenía opinión de santa, a lo cual contribuyó mucho la catalepsia. Creyéronla muerta varias veces, y hasta trataron de enterrarla en una ocasión; mas durante las exequias volvió en sí, pronunciando un nombre, que interpretaron todas las monjas como una señal de santidad, pues entendían que repetía las palabras de Jesús: «iLázaro, despierta!» (391).

Durante uno de sus muchos éxtasis, dońa Paulina vuelve a perder la conciencia pero de manera definitiva. Las monjas, para no equivocarse, esperan un tiempo prudente antes de enterrarla, y cuando ya lo hacen parecen estar muy seguras de que la santa ha fallecido:

Uno de esos éxtasis fue tan largo, que las monjas sospecharon que no saldría de él. Así fue en efecto: no volvió en sí. Pero las monjas, por no exponerse a un nuevo chasco, esperaron lo más posible, y al fin decidieron a enterrarla, seguras de que estaba bien muerta (391).

En el Libro de la vida, santa Teresa se presenta víctima de diversas enfermedades de las que no consigue nunca restablecerse plenamente. El 15 de agosto de 1539, cuando contaba veinticuatro ańos, sufre un coma profundo que se prolonga por espacio de cuatro días, después de los cuales vuelve en sí y se despierta. Durante esos cuatro días la dan por muerta e incluso las monjas de su convento la preparan para enterrarla, echándole cera sobre los párpados para evitar que los ojos se le abrieran y asignándole una sepultura dentro del monasterio:

Diome aquella noche un parajismo, que me duró estar sin ningún sentido cuatro días, poco menos. En esto me dieron el Sacramento de la Unción, y cada hora u momento pensaban espiraba, y no hacían sino decirme el credo, como si alguna 
cosa entendiera. Teníanme a veces por tan muerta, que hasta la cera me hallé después en los ojos. La pena de mi padre era grande de no me haber dejado confesar; clamores, oraciones a Dios, muchas, Bendito sea Él que quiso oírlas, que tiniendo día y medio abierta la sepultura en mi monasterio, esperando el cuerpo allá, y hechas las honras en uno de nuestros frailes fuera de aquí, quiso el Señor tornase en mí (31b).

Galdós, sin duda, conocía este episodio de la santa de Ávila, y de alguna manera lo atribuyó a su personaje, especialmente en sus últimos años de vida. Pero, para esa cuestión, nuestro novelista pudo haberse inspirado en otro tipo de fuentes, los tratados sobre la catalepsia y la histeria escritos por neurólogos y ginecólogos franceses antes de la aparición de Jean-Martin Charcot y su discípulo Sigmund Freud.

\section{LA CATALEPSIA Y LA HISTERIA}

Hacia la primera mitad del siglo XIX, la medicina francesa aportó obras claves para el estudio y conocimiento de la catalepsia. Dos de ellas son monográficas, el Traité de la catalepsie (París, 1841), de Claude E. Bourdin, y De la catalepsie (París, 1856), de T. Puel, y otras dos sugieren ya desde el título su relación con la histeria, De la catalepsie, de l'extase et de l'hystérie (París, 1844), que debió de ser una tesis doctoral, de Alexis Favrot, y Électricité animale, prouvée par la découverte des phénomènes physiques et moraux de la catalepsie hystérique, et de ses variétés (París, 1808), de Jacques Henri Désiré Petetin.

Al margen de esas cuatro obras, otras específicamente sobre la histeria, que también proliferaron en ese mismo período, solían incluir un apartado sobre la catalepsia y enfermedades afines ${ }^{17}$. Así, por citar a un autor aducido antes, Pierre Briquet, en su Traité clinique et thérapeutique de l'hystérie, empieza por reconocer, por lo que respecta a su experiencia, que los ataques de catalepsia en mujeres histéricas son muy raros, para acto seguido ofrecer

17. En la Edad Media se estableció una relación, aunque no tan clara, entre las dos enfermedades. Bernardino Gordonio, en su Lilio de medicina, en el capítulo «De la congelación», «la qual Galieno llama catalepsia», intenta diferenciarla de la «sufocación de la madre» (99). A partir del siglo XVI, en cambio, empezó a generalizarse esa relación, como lo demuestra, por ejemplo, Giovanni Marinelli, Le medicine partenenti alle infermità delle donne (Venecia, 1562), traducida al francés por Jean Liébault como Thresor des remèdes secrets pour les maladies des femmes (París, 1587): «Sembable en cela [la sufocación de la madre] à sincope, apoplexie, epilepsie, catalepsie, lethargue» (410). 
datos concretos tanto obtenidos por él mismo como aportados por otros médicos, en los que el número de casos no supera la cifra de doce:

Les attaques de catalepsie sont assez rares chez les hystériques; je ne les ai observées que chez deux malades. M. Landouzy n'a pu réunir que douze faits de ce genre qu'il a extraits de l'ouvrage intéressant du docteur Bourdin sur la catalepsie, et de la thèse de M. Favrot sur le même sujet. Petetin (de Lyon) n'en rapporte que quatre. Les autres auteurs n'en citent pas non plus de nombreux exemples (404).

En seguida, y a pesar de la estadística, concluye que los "phénomènes caratéristiques de catalepsie» pueden acompañar «les attaques d'hystérie», y reproduce la hipótesis de Etienne-Jean Georget, formulada en Mémoire sur l'hypocondrie et l'hystérie (París, 1824), de que la catalepsia no es más que una forma de histeria, pero la rebate ipso facto al entender que las dos enfermedades son muy diferentes (404). Sin embargo, acaba admitiendo entre ellas «une certaine affinité» unánimemente aceptada por todos los médicos expertos en la materia. Así, pues, considera la catalepsia como una fase posterior de la histeria, como una complicación de esa segunda enfermedad, y cree que muy raras veces la segunda antecede a la primera:

Le plus ordinairement, la catalepsie se joint à l'hystérie déjà préexistante, et les attaques, qui, dans les premiers temps, se bornaient à des simples convulsions, s'accompagnent ensuite $d u$ coma et de la roideur cataleptique. Cette complication indique d'une manière évidente une augmentation des troubles de l'encéphale. Dans des cas bien plus rares, la catalepsie existe la première, et, sous l'influence d'affections morales, l'hystérie vient s'y joindre; on comprend assez difficilement que les influences morales sous l'empire desquelles naît la catalepsie chez les femmes, ne produisent pas en même temps chez elles les phénomènes de l'hystérie (406).

En el párrafo inmediatamente anterior, basándose en T. Puel, Briquet especifica la naturaleza de esas afecciones morales, entre las que incluye los amores desgraciados:

Dans le travail de M. Puel, on voit que les causes de la catalepsie sont toujours des affections morales tristes, des chagrins, l'amour malheureux, la haine, la jalousie, la terreur et les mauvais traitements. Il n'y a donc rien d'étonnant, après de tels faits, que la catalepsie survienne chez les hystériques (406). 
Al final del capítulo menciona los fenómenos con los que suele combinarse o mezclarse la catalepsia, y entre ellos destaca los «extases». Por eso a renglón seguido empieza un nuevo capítulo, titulado "Attaques d'extase», y del que ya hemos hablado arriba, en que define qué es un 'éxtasis histérico' y qué circunstancias lo provocan:

On entend par extase hystérique un état d'excitation cérébrale portée à un point tel, que l'attention concentrée sur un seul objet produit l'abolition temporaire des autres sensations et celle des mouvements volontaires. Cet état, provoqué par la contention prolongée de l'esprit sur un seul objet, n'était pas rare aux époques où la direction de la pensée vers les idées religieuses et la vie claustrale, étaient des choses très communes chez les femmes (409).

Un poco más abajo distingue entre los ataques precedidos por los espasmos y convulsiones histéricas, y los que se manifiestan bruscamente «sans aucun prodrome» (410). También parece diferenciar tres tipos de estado al que llegan las enfermas que padecen esos ataques: un estado de cierta inconciencia, otro de coma y un tercero de letargia. En el primer estado, presenta a las mujeres insensibles pero con capacidad de habla y de movimiento:

Les malades perdent brusquement la connaissance; leurs rapports avec les objets qui les entourent cessent d'exister, leurs sens sont complètement abolis, elles ne voient plus, n'entendent plus, ne sentent plus les corps ambiants. Leurs yeux ouverts, fixes ou convulsés en haut, semblent regarder quelque chose; la parole et les mouvements sont conservés, leur attitude est ordinairement limmobilité... (410).

En el segundo estado, bastante más excepcional que el primero y que puede durar de varias horas a cuatro días, describe a las pacientes sumidas en un sueño profundo y con respiración muy fatigosa:

Je n'ai vu les attaques comateuses que sur cinq hystériques. Elles débutaient de la même manière que les attaques ordinaires, puis, au bout de quelques instants, apparaissaient les phénomènes $d u$ coma, le sommeil était profond, la respiration était stertoreuse, l'assoupissement était si complet, que les malades restaient insensibles aux excitations les plus fortes (417). 
En el último estado, incluye a las enfermas que sufren una muerte aparente y que, por tal razón, corren el riesgo de ser enterradas vivas:

Les attaques de léthargie se voient plus fréquemment que les deux espèces précédentes, et comme elles s'accompagnent d'un phénomène très frappant, la mort apparente, elles ont fixé davantage l'attention des observateurs. Il n'est, en effet, question, dans les ouvrages, que de femmes près d'être mises en terre, et qu'un pur hasard a empêchées d'être définitivement enterrées (417).

A ese propósito, recuerda numerosos casos, tanto antiguos como contemporáneos, de mujeres que habían sido víctimas de un ataque histérico y que, al entrar en un coma profundo, habían estado a punto de ser enterradas con vida. Entre otros, cita el ejemplo de una mujer a quien dieron por muerta durante seis horas al quedar «sans respiration et sans pouls appréciable» (419).

Un poco antes que Briquet, Marc-Hector Landouzy había publicado un Traité complet de l'hystérie (París, 1846), por el que recibió un premio de la Académie Royale de Médecine y en el que ya había establecido claras conexiones entre la catalepsia y la histeria. En el apartado de «Symptômes en général», describía los ataques convulsivos combinados con "une immobilité générale, ou des phénomènes de catalepsie dans un seul membre» (29), y, bastante después, registraba todos los casos de histeria complicada por la aparición de otras enfermedades. En ese sentido dedicaba un apartado a la «Hystérie compliquée de catalepsie», en que distinguía entre formas de histeria en que la catalepsia se manifiesta al final (como el grado más intenso de la primera enfermedad), en que la catalepsia sobreviene al principio o en que, finalmente, puede desembocar en epilepsia. Siguiendo a Bourdin, consideraba que los ataques histéricos se pueden mezclar con los catalépticos de dos maneras diferentes: o bien el ataque general empieza con movimientos convulsivos que enseguida son reemplazados por una inmovilidad total y absoluta, o bien la rigidez cataléptica se presenta en un primer momento para dar paso a los 'accidentes histéricos'. Como hará después Briquet, aunque sin otorgar un papel tan crucial a la religión, creía que la mezcla de esas dos enfermedades podía deberse a una «surexcitation morale et l'état d'extase» en que habitualmente caían las pacientes (155).

En fechas próximas, J. L. Brachet, en su Traité de l'hystérie (París y Lyon, 1847), no se mostraba tan partidario de establecer conexiones entre las dos enfermedades. Empezaba por afirmar que «la rigidité immobile» de la 
catalepsia no se parecía «en rien aux convulsions de l'hystérie», para, sin embargo, admitir que "Quelquefois les deux maladies s'associent», aun teniendo claro que «il est toujours facile de faire la part des phénomènes appartenant à chaque affection» (400).

En otro tipo de obras también solían relacionarse las dos enfermedades. Así, Scipion Pinel, en su Traité de pathologie cérébrale (París, 1844), distinguía un tercer grado dentro de la histeria que presentaba muchas afinidades con la catalepsia:

Les malades peuvent offrir aussi les phénomènes que nous avons observés dans la catalepsie (415).

En un tratado sobre el matrimonio, titulado Hygiène et physiologie du mariage (París, 1848), de enorme popularidad en la época, por el número de reimpresiones que se hicieron hasta finales de siglo, su autor, Auguste Debay, establecía, en el capítulo dedicado a la histeria, una clara conexión entre la religión y la catalepsia:

La contemplation ascétique produisant des hallucinations, des extases, la catalepsie, l'anesthésie, etc. (306)

Lo mismo hacía Jean Baptiste-Félix Descuret, en La médecine des passions (París, 1841), traducida al castellano por Monlau (Barcelona, 1842), que en las dos versiones tuvo un gran éxito editorial. Descuret vinculaba la histeria y la catalepsia con los problemas menstruales:

Si une menstruation difficile détermine quelquefois... l'hystérie, la catalepsie et autres névroses, on voit également ces maladies, et une foule d'autres plus ou moins rebelles ${ }^{18}$.

Incluso en obras de carácter divulgativo, como el Dictionnaire des sciences médicales (recuérdese, de 1818), se admite que la histeria puede dar lugar a diferentes complicaciones, entres las que se mencionan «la catalepsie, la phtisie» (249), o como el Dictionnaire de Médecine et de Thérapeutique Médicale et Chirurgicale, de E. Bouchut y Armand Després, publicado desde 1867, en solitario por el primero de los dos médicos, y a partir de 1873 conjuntamente, se deja claro que «Les attaques d'hystérie produisent souvent la catalepsie» (755). El segundo de los diccionarios, conviene

18. Cito por la segunda edición, revisada y aumentada, de 1844, p. 82. 
recordarlo, también lo había traducido al castellano el médico barcelonés Monlau (Madrid, 1878), pero de su tercera edición, corregida y aumentada, de 1877.

\section{OTROS SÍNTOMAS DE LA ENFERMEDAD DE PAULINA}

El día siguiente a la llegada de Lázaro, en que, como ya hemos visto, lee por equivocación a santa Teresa, dońa Paulina empieza a experimentar síntomas que ponen de manifiesto un cambio importante en su vida. Explica a Clara algunos de esos síntomas, que la Porreño atribuye a una mala alimentación a causa del ayuno:

No estoy buena -dijo la mujer mística restregándose entrambos ojos, como si los tuviera doloridos por la vigilia o cansados de mirar-. Siento un calor aquí dentro... y una agitación... Pero es del ayuno, hermana; es del ayuno (215).

Briquet no sabe hasta qué punto una buena o mala alimentación puede predisponer a la histeria. En ese sentido recuerda diversas teorías según las cuales las mujeres peor alimentadas tienen más posibilidades de padecer esa enfermedad. Opina, basándose en la estadística, que las mujeres de las clases ricas son más proclives a la histeria que las mujeres de las clases pobres, pero acaba preguntándose «combien peu, en général, mangent les jeunes filles des classes aisées» (115). En un apartado sobre la etiología de la enfermedad, en el punto décimotercero, concluye: "le régime de vie dans lequel l'alimentation est insuffisante conduit plus à l'hystérie qu'un régime trop succulent» (162).

En casa del clérigo don Silvestre, doña Paulina ve pasar una procesión religiosa y se halla acompañada por su prima Salomé, su tía María de la Paz y Lázaro. Al sentirse tan cerca del joven aragonés, pues compartía balcón con él, la santa es víctima de una "gran agitación» (241), y poco antes de abandonar la casa del clérigo da muestras de una alteración mucho mayor, que no pasa desapercibida a sus acompañantes. Está con «los ojos encendidos» y con «el aliento penoso» (254), con «mucha fiebre», y apenas puede tenerse en pie (255). Al llegar a su casa, no puede dar un paso más y Lázaro, al notarla con el semblante "demudado", con los ojos cerrados y con los brazos «flojos y caídos» (257), la coge por la cintura, para evitar que caiga al suelo, y la sube en brazos hasta el piso, donde la deja en su habitación. Esa misma noche, el aragonés recibe la visita de la enferma, en cuyo rostro 
reconoce «las señales del insomnio y la fiebre» (259); Lázaro le pregunta primero si está enferma para luego recordarle que «la santidad con exceso es perjudicial»; la Porreño dice estar bien de salud, pero, ante la recomendación de reposo, admite que no puede dormir y que «hace muchas noches que no cierra los ojos» (259). Al tener el ánimo ocupado en sus celos por Clara, el sobrino de Coletilla no se da cuenta, y a cambio sí lo hace el narrador, de «las raras señales de alteración física y moral» que exhibe la faz de dońa Paulina. Durante el diálogo con el joven aragonés, la santa se suelta su larga cabellera negra pero debe apoyarse en la pared de la habitación dando «muestras de gran postración y abatimiento» (268); el muchacho, al tomarle las manos, nota en ellas "un calor excesivo", y al tocarle la frente cree "tocar un cuerpo inflamado" (268), pero, al mismo tiempo, aprecia que toda ella tiembla, "como si su cuerpo recibiera la impresión del hielo» (268), para concluir que "tiene convulsiones». Antes de separarse del aragonés, por la irrupción de su tío, la mística llega a estrechar con violencia el cuerpo de su interlocutor.

Los síntomas que presenta Paulina pueden ser confusos, pero es que los de la histeria lo eran, al menos para la medicina de la época. Landouzy, citando al médico inglés del siglo XVII Thomas Sydenham, reconocía «symptômes si variés, si multiples de l'hystérie», para entre paréntesis reproducir las palabras de su fuente latina, "tam diversa atque ab invicem contraria specie variantia, quam nec Proteus lusit unquam, nec coloratus spectatur chamaeleon» (245), y asimismo Brachet afirmaba que todas las enfermedades nerviosas, incluida la histeria, representaban un «véritable Protée, qui, changeant de forme à chaque instant, ou prenant sans cesse, comme le caméléon, une couleur nouvelle» (257). Leopoldo Alas Clarín, en Su único hijo (Madrid, 1891), atribuye la misma idea al doctor Basilio, quien, tras prestar mucha atención a la variedad de los síntomas referidos por Emma, concluye que "el histerismo es un Proteo», porque «el histerismo, como Proteo, toma infinidad de formas» ${ }^{19}$.

Aun reconociendo ese carácter de la enfermedad, Galdós menciona unos cuantos síntomas, por más que un tanto equívocos, que se pueden corresponder con los de la histeria. Cuando el narrador se refiere a un "aliento penoso" no creo que aluda a problemas de aliento, tal y como lo entendemos en la actualidad, es decir, de halitosis, sino a dificultad de respiración, traduciendo el término francés "anhélation», usado, sin ir más lejos, por Brachet para describir unos de los síntomas de nuestra enfermedad:

19. Ed. Juan Oleza, Cátedra, Madrid, 1998, p. 305. También Charcot, como me recuerda mi amigo y colega Xavier Tubau, recoge esa tradición en sus Leçons de mardi (1887-1888): «on nous parle après cela de l'hystérie protée insaisissable» (en L'hystérie, ed. E. Trillat, L'Harmattan, París, 1998, p. 110). 
«Les palpitations, anhélations, spasmes, convulsions...» (260). Por su parte, Briquet, aunque con otras palabras, también ofrece ese síntoma, que vincula con el asma: "respiration gênée, courte, sibilante, avec augmentation de la dyspnée lors de la parole» (250).

Lázaro, que no advertía muchas de las alteraciones de la enferma, al menos aprecia las "convulsiones» y la fiebre, y ésos eran dos síntomas que se asociaban con frecuencia a la histeria. El primero de ellos se ha mencionado sin excepción desde los médicos de la antigüedad a los del siglo XIX, y no ofrece ninguna discusión, mientras que el segundo no se ha reconocido siempre con unanimidad. Ya Briquet admite una «fièvre nerveuse particuliére» (493), que distingue, por ejemplo, "d'une simple fièvre inflammatoire», de origen tifoideo, por su persistencia "de trois à six mois» (493), y que caracteriza acompañada por "la chaleur de la peau».

Durante su último encuentro con Lázaro, al sentirse rechazada, Paulina padece otro ataque importante. De hecho, cuando el joven aragonés se presenta en la casa de las Porreńo para avisar a su tío, a quien cree en peligro porque ha desbaratado sus planes de atentar contra los liberales, halla a una Paulina muy desmejorada por "tres días de calentura y delirio», ante quien siente miedo por «sus ligeras convulsiones» $\mathrm{y}$ «su agitada respiración» (374). En el transcurso de ese último encuentro, la Porreño le confiesa que es rica, pues ha conservado en su reclinatorio once onzas de oro que descubrió tras la muerte de su tío, y se las ofrece para escapar juntos, pensando, y así se desprende de sus palabras, en el matrimonio. Sin embargo, el sobrino, que aún no acaba de entender a la mística, le contesta que no puede ser, y Paulina, ante semejante contrariedad, sufre la primera parte de su ataque:

Asemejábase a los enfermos atacados de epilepsia cuando están a punto de caer en un angustioso paroxismo. Una contracción producida, al parecer, por el hábito de la sonrisa; una tensión violenta de los párpados como quien expresa el último grado de asombro; palidez mortal, interrumpida por súbitas inflamaciones de rubor; voz semejante a un quejido fatigoso y animada de repente con vibración desentonada, eran los caracteres de su dolencia, próxima a llegar al período de mayor exacerbación (380).

A pesar de todo, la dama se recupera para al menos no dejar ninguna duda respecto a sus sentimientos: «iNecio, no ves que te adoro!» (380), le confiesa a Lázaro; pero, al oír de nuevo decir a su amado que era imposible la realización de semejante plan, cae desplomada y entra en un coma aún no demasiado profundo: 
La devota inclinó la cabeza, agitó los brazos, soltando la caja; se doblegó después de vacilar un momento, retrocediendo y avanzando; dio un giro y cayó al suelo. Su cuerpo hizo retemblar el piso; las monedas se esparcieron en derredor suyo; movió repetidas veces la cabeza, afectada, al parecer, de un profundo dolor interno; llevose ambas manos al pecho, crispando los dedos, y, al fin, quedó quieta, sin más movimiento que las expansiones violentas de su pecho sacudido por una respiración fuerte y ruidosa (381).

En ese momento, María de la Paz y Salomé abren la puerta y contemplan atónitas el espectáculo de Paulina tendida en el suelo junto a una gran cantidad de monedas de oro. Tras averiguar la procedencia del dinero, y sin preocuparse para nada de la enferma, se enzarzan en una pelea, de la que sale vencedora la sobrina, que huye, con el dinero, escalera abajo. Lázaro, al verse increpado por la tía, que lo hace responsable de su derrota, abandona la casa, no sin antes echar un vistazo a la devota, que "permanecía aún sin movimiento" (384).

Por lo que parece, Paulina no sufre en ese momento, y no sabemos qué le ocurre inmediatamente después, un ataque de catalepsia: ha perdido el conocimiento, de ahí que haya caído, pero conserva signos evidentes de vida, como los de una respiración estentórea y ruidosa. El estado al que ha llegado la Porreño se corresponde con el segundo tipo de ataque de que puede ser víctima una histérica, tal y como lo describe Briquet: «Elles débutaient de la même manière que les attaques ordinaires, puis, au bout de quelques instants, apparaissaient les phénomènes du coma, le sommeil était profond, la respiration était stertoreuse».

\section{EL MISTICISMO DE MADAME GERVAISAIS Y MARTHE ROUGON}

Los hermanos Goncourt, Jules y Edmond, publicaron en la década de los sesenta cuatro novelas que tenían como protagonistas a otras tantas mujeres: Renée Mauperin (1864), Germinie Lacerteux (1864), Manette Salomón (1867) y Madame Gervaisais (1869). Todas ellas presentan un carácter especial, de tipo nervioso, con ataques convulsivos y con pérdidas de conciencia, ya sea por letargia o síncope, pero la que mayor interés tiene, para nuestro propósito, es la última, Madame Gervaisais, porque, aunque en circunstancias diferentes, busca refugio en la religión y el misticismo.

Madame Gervaisais es una mujer de treinta y siete años, viuda, con un hijo discapacitado, que se llama Pierre-Charles. Viaja a Roma para tratarse 
su tuberculosis, y una vez allí, seducida por el ambiente religioso del lugar, experimenta una conversión al catolicismo. En sus momentos de soledad evoca su juventud en compañía primero de un padre viejo y después de un marido a quien no amó pero con quien se casó para complacer a su progenitor. Era su relación con el cónyuge muy insulsa, porque no le inspiraba ningún tipo de sentimiento, ni bueno ni malo, sino todo lo contrario:

Et elle repassait ces tristes premières années grises de son mariage, ces années vides, patientes, résignées, monotones, d'une union sans amour, sans amitié, sans estime; ces années avec cet homme, un homme qui n'était ni bon ni mauvais, ni aimant ni égoïste, ni jeune, ni vieux, ni beau ni laid, mais qui était nul, d'une de ces nullités que certains hauts fonctionnaires, sortis de leur bureau et de la société, trahissent et semblent débrider au foyer conjugal $(135)^{20}$.

Durante los diez años que duró su matrimonio la dama parisina buscó consuelo en los libros, y sólo ya al final tuvo el hijo que tanto había deseado para resarcirla del sufrimiento:

Et cela pendant dix ans!' Dix ans pendant lesquels elle sétait réfugiée dans la distraction sèche et la consolation austère des livres; dix ans où, comme la Rachel de l'Écriture, elle avit crié vainement à son bourreau: "Monsieur, donnez-moi des enfants... ou j'en mourrai!» Dix ans sans être mère! Enfin, elle avait eu cet enfant-là... (136).

A lo largo de su estancia en Roma Madame Gervaisais pasa una serie de vicisitudes que la acercan progresivamente al catolicismo. En su segundo año en la ciudad decide asistir, acompañada por su hijo, a todas las ceremonias de la Semana Santa desde el Domingo de Ramos al Domingo de Resurrección. Vive con especial emoción cada una de esas ceremonias, al igual que, por ejemplo, las vivirá la jueza dońa Fe al lado de su hijo en El diablo en semana santa de Clarín ${ }^{21}$.

Un poco después Madame Gervaisais se desvive por la educación de su hijo, a quien obliga a un gran esfuerzo intelectual, al intentar enseñarle a leer.

20. Para la edición de Madame Gervaisais he utilizado la de Marc Fumaroli, Gallimard, París, 1982. Es por ella que siempre cito el texto sin ninguna otra referencia.

21. Véase Ángeles Ezama, ed., con un estudio preliminar de Gonzalo Sobejano, Leopoldo Alas, «Clarín», Cuentos, Crítica, Barcelona, 1997, pp. 3-13, y Simone Saillard, «Ana Ozores, de la mystique a l'hystérie», p. 70. 
De resultas de semejante esfuerzo, el niño padece una 'fatiga cerebral' (152) y su vida corre peligro. La madre, aconsejada por unas amigas romanas, visita el santuario de san Agostino, dedicado al culto de la «Madonna del parto", famosa por sus milagros. Después de dos días, el médico que atiende a Pierre-Charles anuncia a su madre que el niño se ha salvado, y considera tan sorprendente curación un milagro de la Virgen.

Estando su hijo completamente recuperado de su enfermedad, la dama parisina decide pasar los meses de julio y agosto en Castel-Gandolfo, donde entabla relación con la condesa rusa Lomanossov, quien está a punto de ingresar en el monasterio del Sagrado Corazón, a la espera de cumplir los treinta años, edad en que ha fijado su renuncia a este mundo. En ningún momento la condesa trata de convencer a la dama francesa para que se convierta al catolicismo, pero comparte con ella su entusiasmo, casi místico, y sus creencias religiosas. Al regresar a Roma, tras el verano, Madame Gervaisais empieza a experimentar una metamorfosis, al estar enternecida por el ejemplo de amor divino de la condesa, aunque aún se resiste a asumir ciertos dogmas de la religión católica. Lee a san Francisco de Sales y asiste a misa todos los domingos, siempre acompañada por su hijo.

Poco a poco va superando todos los obstáculos de su fe y el día de santa Ágata anuncia su conversión definitiva y completa. Por ello busca un confesor, y el elegido es el jesuita Giansanti, con quien se confiesa todos los martes y viernes por el espacio de dos horas. A la vez que abandona, también de manera paulatina, los círculos romanos que hasta entonces había frecuentado, intensifica sus visitas a su confesor, ahora cuatro veces por semana.

Por la insistencia de un amigo, llamado Schnetz, reaparece un domingo en una velada musical, durante la cual se asoma a una ventana de la sala para poder respirar mejor. Se acerca a ella un tenor italiano, quien, involuntariamente, la llega a rozar, pero sin dirigirle la palabra. La parisina, muy ofendida, coge a su hijo y se marcha. Ha creído, dentro de su mente enfermiza, que el cantante se le había insinuado, y desde ese momento se supone víctima de los deseos más impuros por parte de todos los hombres que la miran:

Elle avait eu comme l'hallucination d'une déclaration d'amour, d'une offense approchée d'elle. Cette idée senfonçait et germait en elle, sans que rien pût expliquer ces singulières alarmes de l'honnêteté et de la conscience chez une femme d'une si entière pureté, d'un si austère veuvage de pensée même. A partir de cette soirée, elle se figura, pendant longtemps, répandre 
autour d'elle un appétit de volupté, attacher la tentation à tous ceux qui la regardaient, provoquer leurs désirs, attaquer, sans le vouloir, leurs sens, mettre en eux, par la vue de sa beauté, tout effacée et passée qu'elle la croyait, la passion impure (208).

Con tales imaginaciones exige a la religión que acaba de abrazar una mayor dureza y una penitencia más severa. Así, busca un nuevo confesor, uno de Capitolio, que esté acostumbrado a tratar con delincuentes y, por consiguiente, a imponer las penas más duras. Al final lo encuentra, tras algunos meses, dentro de la orden de los Trinitarios. El hombre se llama Sibilla, a quien Madame Gervaisais logra convencer, para que se convierta en su guía espiritual, gracias a la recomendación de la mujer de un ministro extranjero. El trinitario la maltrata y humilla, la mortifica y degrada, haciéndola sentir un ser menospreciable. La somete a un ejercicio espiritual, que consiste en leer todos los días un capítulo del Antiguo Testamento y otro del Nuevo, empezando respectivamente por el Génesis y por el evangelio de san Mateo. Al cabo de unos meses, la dama parisina tiene la necesidad de trasladarse al barrio en que vive su confesor, y el cambio de casa aún la aísla más del mundo de sus antiguos amigos de Roma. Es la época en que Madame Gervaisais, ayudada por su enfermedad, la tuberculosis, vive en perpetuos éxtasis, en los que se transforma en Dios y en los que, al conseguir semejante metamorfosis, es objeto de una especie de catalepsia:

La maladie, la lente maladie qui éteignait presque doucement la vie de $M^{m e}$ Gervaisais, la phtisie, aidait singulièrement le mysticisme, l'extatisme, l'aspiration de ce corps, devenant un esprit, vers le surnaturel de la spiritualité...

Elle entrait pleinement dans la relation directe et incessante, dans cette sorte d'identification avec l'Infini, par une absorption, au delà de toute idée et de tout mot humain, où s'engloutissait son cour. Toute morte à ce qui est le moi pensant et actif d'une personne, sa sensitivité suspendue par une étonnante et miraculeuse paralysie, une véritable catalepsie sainte (241242).

Es la época en que, precisamente por esos ataques que la dejan como muerta, la parisina anhela constantemente la muerte: por tal motivo un domingo, y en la compañía de su hijo, decide descender a las catacumbas para recorrer sus galerías y pasillos. Un día la sorprende la llegada a Roma de su hermano, que, al corriente de la transformación experimentada por su hermana, intenta distraerla, devolviéndola al mundo del que ella fue 
arrancada por la religión. El hermano también trata de convencerla para que regrese a París, y madame Gervaisais accede a semejante deseo sólo con una condición, la de ser recibida en audiencia por el papa. Durante la visita al Vaticano, embargada por la emoción, al abrirse la puerta tras la que esperaba su santidad, cae muerta.

En ningún momento los hermanos Goncourt emplean el término histeria o histerismo para calificar los ataques de éxtasis que llega a sufrir su protagonista. Sin embargo, como han notado sus editores, para caracterizar la catalepsia de la dama parisina, se apoyan en la obra de Alexis Favrot sobre esas dos enfermedades. Sugieren que los síntomas más claros de su enfermedad, la de la histeria, no la tisis, se ponen de manifiesto en Roma, después de convertirse al catolicismo y ser víctima de los primeros arrebatos de misticismo. En cualquier caso, antes de ese punto de inflexión en su vida, madame Gervaisais ya había pasado por experiencias negativas, al haber estado casada con un hombre a cuyo lado no había logrado ser feliz, ni, por supuesto, sentirse satisfecha en todos los aspectos, incluido el sexual.

Es difícil precisar hasta qué punto Galdós pudo inspirarse en el personaje de los novelistas franceses para el suyo de doña Paulina. El autor canario había comenzado La Fontana de oro unos meses antes de la publicación de Madame Gervaisais, pero pudo tener tiempo de leerla antes de acabar su obra. No es que la dama francesa y la Porreño sean personajes idénticos, pero sí guardan cierta relación. Las dos mujeres son treintañeras y pertenecen a la aristocracia, pero han sido educadas de manera muy diversa: la francesa ha leído toda clase de libros, incluidos los de filosofía tanto antigua como moderna, ha asistido a la ópera, mientras la española ha recibido una educación religiosa en casa de sus tíos, en la que no ha aprendido más que a rezar. Las dos mujeres han tenido una vida desdichada, una casada con un hombre al que no amaba, la otra consagrada desde nińa a una devoción que poco se avenía con su temperamento. Las dos han hallado refugio, para su infelicidad, en la religión, pero a edades y en circunstancias muy diferentes.

Madame Gervaisais en cierta medida preludia La conquête de Plassans de Émile Zola, y las dos influyen claramente en La Regenta de Clarín, como ha demostrado la crítica francesa en los últimos años ${ }^{22}$. La conquête es la cuarta novela que su autor dedicó al ciclo de la familia Rougon-Macquart, y se publicó en folletones entre febrero y abril de 1874 (en 1876 salió en un solo volumen ${ }^{23}$. La protagonista, Marthe Rougon, al igual que Madame

22. Véase especialmente Robert Jammes, "La conquête de Plassans de Émile Zola, hipotexto de La Regenta", en Realismo y naturalismo en España en la segunda mitad del siglo XIX, ed. Yvan Lissorgues, Anthropos, Barcelona, 1988, pp. 385-399.

23. Uso la edición de Colette Becker, Fasquelle, París, 1999, por la que siempre cito a 
Gervaisais, al comienzo de la obra, ha cumplido treinta y siete años, pero no tiene solo un hijo sino tres, de los cuales la nińa pequeña, Désirée, con catorce años, también padece un retraso mental. Está casada con un primo hermano, François Mouret, a cuya vera lleva una vida anodina y muy monótona. Contrae matrimonio con él porque la familia, dado su parecido físico, cree que el uno está hecho para el otro, pero no porque ame de verdad a su futuro marido.

El matrimonio vive en una casita de una ciudad de provincias, cuyo nombre Zola se ha inventado (es el de Plassans), y es, aunque sólo en apariencia, más o menos feliz. El marido alquila el segundo piso de la casa a un cura, el padre Faujas, que llega acompańado por su madre desde Besançon. El nuevo sacerdote conquista primero la casa de sus inquilinos y después toda la ciudad: se sirve de Marthe para llevar a cabo sus dos proyectos, y lo hace charlando con ella cada noche después de cenar, mientras Mouret juega a las cartas con la madre del cura. En esos diálogos, Faujas, además de conmover a su interlocutora con la narración de historias tiernas, le habla del plan de dedicar un edificio para acoger a las niñas más pobres y descarriadas de Plassans a quienes sus progenitores, por razones diversas, no pueden prestarles demasiada atención (se llamará la 'obra de la Virgen'). Mientras lleva a la práctica esa empresa Marthe siente la llamada de la religión y experimenta una conversión igual de sorprendente que Madame Gervaisais.

Marthe necesita un confesor, y para ese papel piensa en el padre Faujas, pero su inquilino no acepta y le propone que se confiese con otro sacerdote, el padre Bourrete. Sin embargo, con el paso del tiempo, la casera logra que Faujas se convierta en su guía espiritual, y bajo su tutela vive la religión con un ardor poco común entre las feligresas de la ciudad. De estar todo el día encerrada en casa ha pasado a andar fuera, especialmente en la iglesia. Deja de ocuparse de su familia: permite que sus hijos se vayan, incluida la pequeña Désirée, a quien el padre envía con su nodriza. Por las noches, sufre grandes ataques de no sabe muy bien qué, pero el caso es que grita, se tumba en el suelo y se golpea. Los inquilinos de la casa creen que su señora es víctima de las agresiones de su marido, y por eso buscan el modo de hacer que lo encierren en un manicomio. Cuando han conseguido su propósito, se apoderan de la casa, y cuentan con la connivencia de Marthe, cada vez más enamorada de su confesor.

De hecho, antes del encierro de Mouret, su esposa vive las ceremonias religiosas con una devoción extraordinaria. Consagra todas las horas a la plegaria, arrodillada en las iglesias, oyendo la música del órgano, oliendo

partir de ahora. Existe una traducción al castellano por Esther Benítez, Alianza Editorial, 1982. 
los cirios encendidos de las capillas. Da rienda suelta a sus sentimientos, a través de la religión, y ya pone de manifiesto ciertas reacciones inquietantes, al quedar inerme, como muerta:

Elle entra enfin dans les délices du paradis. Elle eut des attendrissements, des larmes intarissables qu'elle pleurait sans les sentir couler; crises nerveuses, d'où elle sortait affaiblie, évanouie, comme si toute sa vie s'en était allée le long de ses joues. Rose la portait alors sur son lit, où elle restait pendant des heures avec les lèvres minces, les yeux entrouverts d'une morte (303).

En esas crisis la criada, Rose, llamaba al padre Faujas mientras ella iba en busca de éter para aplicárselo a su señora. Otras veces las crisis Marthe las sufre en la iglesia, sobre todo durante el transcurso de las ceremonias de un Viernes Santo, en una Semana Santa muy especial para ella, por la devoción con que las vivió:

Quand le dernier cierge expira... elle sévanouit, les flancs serrés, la poitrine vide. Elle resta une heure pliée sur sa chaise, dans l'attitude de la prière, sans que les femmes agenouillées autour d'elle s'aperçussent de cette crise. L'église était déserte, lorsqu'elle revint à elle (308).

Sólo en una ocasión, como en Madame Gervaisais, Zola califica las crisis de Marthe con el nombre de catalépticas, y lo hace, hacia el final de la novela, cuando su heroína está sin su marido, pero a quien parece temer, en un miedo irracional porque ella sabe que Mouret es inofensivo:

Ces peurs se terminaient par des crises de catalepsie, qui la tenaient comme morte, la tête sur les oreillers, les paupières levées (372)

En otros momentos, el novelista francés prefiere el término menos comprometedor de "crises nerveuses», durante cuyo transcurso la enferma quedaba «comme morte pendant des heures» (407). Marthe, además, padece la tuberculosis, que se complica por la manifestación de otra enfermedad que el médico que la trata, el doctor Porquier, designa con el nombre vago de nerviosa:

La pauvre Mme Mouret avait les deux poumons attaqués, et la phtisie chez elle se compliquait d'une maladie nerveuse (429). 
Al no hallar en la religión la paz que buscaba, Marthe siente la necesidad de decirle al padre Faujas que lo ama (395), y el sacerdote, al oír lo que ya sabía, no puede menos que rechazarla, porque, como le había confesado a su madre, quien pensaba que se desfogaba con la señora Mouret, «les hommes chastes sont les seuls forts» (271). Marthe, que ya entonces había cumplido los cuarenta años, le recuerda al sacerdote que su marido nunca le había pegado, y que en esas noches en que gritaba y se tumbaba en el suelo lo hacía porque sufría "brûlures par tout le corps", que intentaba calmar con el frío de las baldosas (394). Al verse tratada cruelmente por el padre Faujas, que ha estado a punto de agredirla, abandona su casa con la intención de ir en busca de su marido, pero, una vez se halla ante él, comprueba que Mouret está realmente loco. Desengañada, decide volver a su casa sola, pero, al encontrarla con los cerrojos echados, debe refugiarse en casa de su madre, donde, después de unas horas, muere en la presencia de su hijo Serge.

Mientras llegaba ese desenlace fatal, Mouret logra escapar del manicomio (de hecho, el tío Macquart había dado instrucciones para que dejaran abierta la puerta de su celda), y se dirige a su casa, en la que consigue entrar tras derribar la puerta del jardín. Una vez en su interior busca a su mujer, pero en su cama halla a la hermana y al cuñado del padre Faujas, quienes a esas alturas se habían apoderado de toda la casa. Al comprobar semejante usurpación de sus bienes, Mouret decide prenderles fuego, y en el incendio mueren todos sus ocupantes, incluido el pirómano.

Para el tipo de locura que padece François Mouret, con intervalos de lucidez, Zola se ha basado en el libro de Ulysse Trélat, La folie lucide (París, 1861), que llegan a citar varios de sus personajes, entre ellos el doctor Porquier:

Le docteur vient de nous réciter là une page d'un livre sur la folie lucide, que j'ai lu, et qui est intéressant comme un roman (333).

El libro se puede leer, en efecto, como una novela, porque su autor refiere muchos casos que él mismo ha tratado en el hospital de la Salpêtrière, y en su análisis a veces reproduce las cartas que las enfermas, sobre todo por amor, le han dirigido a él o a sus amantes, cartas tan apasionadas, confiesa Trélat, como las de Eloisa y Abelardo (132). En esa obra, el médico francés habla también de los «erotómanos» para diferenciarlos de los «ninfómanos» o los «sátiros», especialmente porque los primeros están dominados por un sentimiento, mientras los otros lo están por un placer físico. A los primeros parece conceder el tratamiento de enfermos de amor, porque los supone buscando los lugares apartados, con dificultad para conciliar el sueńo y con 
una pérdida muy evidente del apetito. Además los presenta subyugados por afecciones desordenadas que van del miedo al furor pasando por los celos, y también los caracteriza descuidando y huyendo de la familia, despreciando las convenciones sociales y protagonizando acciones extraordinarias. Acaba reconociendo que los «erotómanos» pueden serlo por leer novelas y que pueden padecer toda suerte de delirios.

El personaje de Marthe participa de muchas de las características de la erotomanía, pero no de todas. Se siente dominada más por un sentimiento que por el deseo de la satisfacción de un placer físico, y por la obsesión que despierta en ella ese sentimiento abandona sus ocupaciones habituales hasta entonces, especialmente la dedicación a sus tres hijos y a su marido. Sin embargo, pone de manifiesto ciertas carencias: a sus treinta y siete años no tiene relaciones sexuales con su marido, y a los cuarenta, atraída por el padre Faujas, siente renacer todas las pasiones adormecidas en sus casi veinte años de matrimonio. Para reprimir esas necesidades se refugia en la religión, cuya llamada experimenta al mismo tiempo que su amor por el sacerdote que la inspira.

Pero Marthe comparte muchos de los rasgos de su abuela Adélaïde, según los expone Zola en el primer volumen del ciclo dedicado a la familia, La Fortune des Rougon, publicado con cierto retraso en octubre de 1871. Adélaïde, a quien uno de sus nietos llamaba cariñosamente Dide, es una mujer con un temperamento nervioso que se manifiesta por sus numerosas crisis a lo largo de su centenaria vida. A los dieciocho años, tras quedar huérfana, se casa con uno de los labradores que había trabajado con su padre, pero enviuda quince meses después de la boda, poco después de dar a luz a su primer hijo, Pierre Rougon. En seguida, mucho antes de cumplirse el año de luto, se amanceba con un contrabandista, Macquart, con quien en veinte meses tiene dos hijos, a pesar de no vivir regularmente con él. En ese período de su vida Adélaïde parece entregarse a otros amantes, pues es una mujer excesivamente voluptuosa, pero, tras la muerte del contrabandista, ocurrida cuando ella ha superado los cuarenta ańos, se encierra en su casita para practicar la más absoluta castidad, y esa situación, nueva e insólita para la mujer, agrava sus crisis nerviosas, que se suceden en forma de catalepsia, según las llama el propio narrador («Elle retombait dans son état de catalepsie...»). La tía Dide, en ningún momento, se refugia en la religión, pero sí es verdad, y en ello insiste Zola, que lleva una vida monacal, consagrada al recuerdo del contrabandista. El novelista francés tampoco la trata de histérica, pero sí usa la palabra, como adjetivo, para ilustrar la fuerza que llegaba a adquirir su personaje durante sus ataques, incluso cuando ya era una septuagenaria: 
Elle avait la force effrayante de ces folles hystériques, quion est obligé d'attacher, pour qu'elles ne se brisent pas la tête contre les murs (175).

En otra ocasión, ya hacia el final de la novela, cuando el médico Pascal, uno de los hijos de Pierre Rougon, halla a su primo Silvère, de la rama Macquart, entre las tropas republicanas, antes de ser sofocadas por las de Luis Napoleón Bonaparte, hablando con entusiasmo de la causa que defendía, le contesta que es digno nieto de su abuela para acabar señalando, ya en voz baja, que semejante entusiasmo puede confundirse con la histeria, y que las dos cosas, en cualquier caso, son manifestaciones de los nervios:

Hystérie ou enthousiasme, folie honteuse ou folie sublime.

Toujours ces diables de nerfs! (263).

Para el personaje de Adélaïde, aunque no sé hasta qué punto, Zola podía haberse inspirado en la protagonista de la novela de Flaubert, Madame Bovary, aparecida en la Revue de Paris entre octubre y diciembre de 1856. Emma, igual de voluptuosa y nerviosa que la tía Dide, también padece de catalepsia, especialmente cuando es consciente de que su amante se ha marchado sin ella, renunciando a la fuga que los dos habían planeado tantas veces. Madame Bovary primero sufre ahogos cuando se entera por su esposo que Rodolphe va a salir de viaje, y después, al oír el paso del carruaje de su amante, que reconoce sin ninguna duda, no puede evitar dar un grito y caer desmayada de espaldas. Tras inhalar un frasco de vinagre aromático, recupera el sentido, pero en seguida vuelve a desvanecerse, y en semejante estado es conducida a su cama, tan inmóvil como antes:

Elle sévanouit encore. On la porta sur son lit.

Elle reste étendue, la bouche ouverte, les paupières fermées, les mains

à plat, immobile, et blanche comme une statue de cire ${ }^{24}$.

En una de las copias manuscritas del texto, tras "On la porta sur son lit », Flaubert había escrito: «Elle y fut prise d'un sommeil lourd, presque cataleptique» ${ }^{25}$. Por razones que desconocemos, decidió suprimir ese pasaje para la edición. Quizá lo consideraba demasiado evidente y un tanto

24. Flaubert, Madame Bovary, ed. Jacques Neefs, Librairie Générale Françoise, París, 1999 , p. 322.

25. Ed. cit., p. 322, n. 1. 
redundante. Durante el período de convalecencia, bastante largo, Emma cambia de estilo de vida y quiere convertirse en una santa. No sólo compra rosarios y libros de piedad, sino que además se consagra en exceso a las obras de caridad.

Los neurólogos ingleses y franceses habían distinguido una especie de locura religiosa, que en su país no había acabado de desaparecer después de la revolución: un tipo de locura en el que caen Marthe y Madame Gervaisais, pero no Adélaïde y Emma Bovary. Philippe Pinel, en su Traité médico-philosophique sur l'aliénation mentale ou La manie (París, 1801), ya distingue un tipo de manía que llama «religieuse» (75), que aconseja curar llevando al enfermo a un lugar espacioso en que quede aislado de los libros, pinturas y objetos relacionados con el culto religioso. Félix Voisin, en Des causes morales et physiques des maladies mentales (París, 1826), incluye un capítulo sobre les «Institutions religieuses» para explicar cómo determinados sentimientos religiosos producen diversas "espèces de manies pieuses», especialmente entre las mujeres (36). William Charles Ellis, en su Traité de l'aliénation mentale, traducido al francés por Théophile Archambault (París, 1840), considera la "folie religieuse » muy común en ciertos países protestantes, como Inglaterra, y también en los católicos, especialmente en la modalidad del misticismo (CIII). Joseph Guislain, en sus Leçons orales sur les phrénopathies (París, 1852), emplea las expresiones de «manie religieuse», «théomanie» $\mathrm{y}$ «monomanie religieuse» para diferenciarla de la "mélancolie de ce nom", teniendo en cuenta que unos exteriorizan los sentimientos de devoción con humildad y temor, mientras que los otros se entregan a una gesticulación desordenada (188).

Pero Zola, como han demostrado sus editores, para la enfermedad de Marthe, se inspiró en las obras sobre la histeria ya mencionadas, en las que tímidamente sus autores la relacionaban con la tuberculosis, siguiendo la idea de médicos anteriores que consideraban la primera enfermedad como la causa más importante de la segunda ${ }^{26}$. Si en Madame Gervaisais la tuberculosis aparece antes que la histeria, en Marthe Rougon, en cambio, se manifiesta después, o tal vez a la par, pero nunca antes; y sólo en Marthe es la causa segura de su muerte, porque Madame Gervaisais parece víctima de una especie de síncope, al vivir una situación demasiado emocionante para ella, como la posibilidad de ser recibida en audiencia por el Papa.

26. Véase sobre el tema Cristina Mazzoni, ob. Cit., p. 60, n. 18, y María Asunción Doménech, Género y enfermedad, p. 98. 
La medicina antigua consideró la histeria como una enfermedad originada en el útero de la mujer, pero la explicaron de manera distinta. Antes de Galeno, los griegos supusieron que el útero era un organismo vivo e independiente, que se desplazaba hacia las partes superiores del cuerpo en busca de un calor y una humedad que no recibía por la vía natural ${ }^{27}$. Al llegar al tórax, al comprimirlo, provocaba una serie de malestares en el paciente, desde dificultad respiratoria hasta dolores precordiales, pero también podía migrar a otras partes del cuerpo. Para devolver el útero al lugar que le correspondía se recomendaba, o bien fumigaciones vaginales, o bien la relación sexual, porque de esa manera se le restituía la humedad perdida. En esta teoría, se introdujeron algunas modificaciones, a partir de la medicina bizantina, que consistían en limitar el movimiento de la matriz a un movimiento exclusivamente local.

Galeno pensó que esa concepción del útero, como órgano independiente y vivo, era, desde el punto de vista anatómico, ridícula y que la causa de la histeria debía explicarse como una retención del líquido seminal, análogo al esperma, debida a la continencia. Ese líquido a la larga, al no ser expulsado, se acababa pudriendo y terminaba afectando a otros órganos del cuerpo, enfriándolo, produciendo espasmos y desfallecimientos. Para evitar esa retención se aconsejaba tener unas relaciones sexuales normales, o, si no, practicar la masturbación. Galeno afirmó que la misma enfermedad, que a menudo se confundió con el priapismo, la podían tener los hombres, especialmente jóvenes, que optaban por la castidad ${ }^{28}$.

Todas estas teorías, a veces revueltas, tuvieron una enorme aceptación a lo largo de la Edad Media. Sólo los grandes representantes de la patrística llegaron a oponerse, al no poder admitir que la castidad, virtud preciada como la que más, podía suponer graves problemas de salud, y así creyeron que, cuando los había, era por el triunfo de las fuerzas del mal. Una buena parte de la histeria fue interpretada como una posesión demoníaca. En el Renacimiento, se aplicaron especialmente las teorías de Galeno, aunque de alguna manera se colaron ideas procedentes de los griegos.

27. Para una historia de la enfermedad, véase Ilza Veith, Hysteria. The history of a disease, University of Chicago, Chicago, 1965, y José Jaime Melendo, "Conceptos generales de la histeria», en Aproximación a la histeria, ed. Salvador Mascarell, Mayoría, Madrid, 1980, pp. 9-31.

28. Véase, por ejemplo, su obra De locis affectis, 414-430; hay varias traducciones al castellano de esa obra, entre las que figura la de Salud Andrés Aparicio, con una introducción de Luis García Ballester, Gredos, Madrid, 1997, pp. 412-423. 
El Barroco conllevó cambios importantes. Un médico francés, Charles Lepois, a principios del siglo XVII, fue el primero que rebatió todas las hipótesis anteriores, al concluir que los síntomas de la histeria, sin excepción, revelaban que la enfermedad se originaba en el cerebro, y no en el útero, como erróneamente se había creído. En cambio, estuvo de acuerdo con Galeno, al afirmar que la enfermedad era común a hombres y mujeres. Otros médicos de ese siglo, como Thomas Sydenham, incluyeron la histeria como una enfermedad de la mente y eligieron para la manifestación masculina el nombre de hipocondría.

En el siglo XVIII, William Cullen acuñó por primera vez la palabra neurosis y la aplicó a la histeria, pero, a pesar de considerarla una enfermedad del sistema nervioso, acabó por entenderla «comme une affection de l'utérus $\&$ des autres parties qui composent le système génital» ${ }^{29}$. Afirmó que era una enfermedad más común entre las mujeres estériles, las viudas y las ninfómanas (quienes padecen la hysteria libidinosa), pero no dejó claro si la terapia sexual era o no era eficaz.

En la primera mitad del siglo XIX, se produjo una fuerte polémica entre los partidarios de las teorías antiguas y de las nuevas ${ }^{30}$. Entre los primeros cabe mencionar a Marc-Hector Landouzy, quien sostiene de forma rotunda que el «appareil génital» es el «siège unique de l'hystérie» (211), aduciendo la sentencia hipocrática "propter solum uterum mulier est id quod est». Por ello, Landouzy habla de la continencia como la causa directa de la enfermedad, distinguiendo entre la continencia por imposición, no deseada, pero reprimida, y la continencia por desconocimiento de los placeres de la carne. Así excluye de la histeria a las prostitutas, aunque no totalmente, como veremos enseguida, y piensa que el matrimonio no es una terapia infalible, porque dentro de él la mujer no siempre halla "satisfaction morale et satisfaction physique, besoins également impérieux de notre nature» (186). Por lo que respecta a la unión sexual, la recomienda, pero sin abusar, porque un abuso de esa práctica puede estimular la enfermedad, como les ocurre a algunas prostitutas (es la ninfomanía o histeria libidinosa):

\section{De linnervation génitale peuvent dériver de l'absence, de} l'abus ou du simple exercice de la fonction sexuelle (188).

29. Institutions de médecine pratique, traducción al francés por Pinel, vol. II, París, 1785, pp. $277-278$.

30. Para un resumen de ese panorama puede verse Jean-Marie Bruttin, Différentes théories sur l'hystérie dans la première moitié du XIXe siècle, Druck, Zurich, 1969, y especialmente Nicole Edelman, Les métamorphoses de l'hystérique. Du début du XIX' siècle à la Grande Guerre, La Découverte, París, 2003. 
En su Mémoire sur l'hypocondrie et l'hystérie, publicado en 1824, EtienneJean Georget negó de forma rotunda la teoría uterina de la histeria para abogar por la cerebral, fijándose para ello más en los síntomas idiopáticos (producidos en el propio cerebro) que en los simpáticos (producidos en otros órganos, como el estómago, útero, etc). Piensa que el matrimonio puede ser un buen remedio, pero no porque permita la práctica de la relación sexual, que en sí misma no cura la enfermedad:

Une erreur grave, commise presque généralement, c'est de croire que le coit exerce en général une très heureuse influence sur la production des attaques, et que ce moyen est le meilleur remède de la maladie elle-même.

Jean Louis Brachet, primero en Les recherches sur la nature et le siège de l'hystérie et de l'hypocondrie (París, 1832), y después en el Traité de l'hystérie (Lyon, 1847), tras un análisis muy minucioso de las diferentes teorías, llegó a restringir «le siège de l'hystérie» "au système nerveux cérébral» (341), y por ende, en el apartado de las terapias, evitó mencionar «les manœuvres indécentes qui ont été pratiquées sur les organes génitaux» (451), omitiendo cualquier referencia al matrimonio. Sólo unos años más tarde, Pierre Briquet, en su obra ya mencionada, de 1859 , también sostuvo que la histeria era una enfermedad del cerebro y que la medicina y la filosofía habían transmitido un error a lo largo de muchos siglos, al considerar la continencia como la única causa de la histeria. Aún así, admitió que determinadas mujeres, estimuladas por el deseo sexual, a través de la lectura de novelas o de conversaciones sobre temas lascivos, pueden sufrir una excitación del sistema nervioso que acaben por producir fenómenos histéricos, o que otras, casadas, que viven con sus maridos, pero con quienes no practican el coito, a consecuencia de la irritación resultante, terminen siendo histéricas (140). A propósito de matrimonio, opinó que podría ser una buena terapia si la paciente, casándose, hallara un bienestar físico y moral, pero lo creyó difícil, por no decir imposible, en una histérica, sobre todo si la joven esposa debe hacer frente a los malos tratos del marido o a las intrigas de sus nuevos parientes (620). En ese sentido, insistió en que el matrimonio no consiste sólo en las relaciones sexuales, "qui ne durent que quelques instants", sino en una relación de pareja que se prolonga en el tiempo, y en que las necesidades, que llamó de 'espíritu' y 'corazón', si no se satisfacen, ocasionan una excitación más continua y permanente que la insatisfacción sexual (622). Por ese motivo concluyó que el matrimonio podía ser útil para la histérica, porque colmaba unas expectativas espirituales más que físicas. 
Unos años antes, en 1848, Auguste Debay había explicado que la histeria nacía por un sufrimiento del útero o la matriz que rápidamente se propagaba "aux nerfs céphalo-rachidiens» (304), pero que su verdadera sede no era el cerebro, sino el útero. Entre las causas que aduce, menciona «l'amour non satisfait» y «l'état de célibat quand on désire le mariage» (305). Ya bastante después, E. Bouchot y Armand Després, en su enciclopédico Dictionnaire de Médecine, si bien mencionaban entre las causas de la enfermedad «l'amour contrarié ou non satisfait et la continence» (755a), al tratar la terapéutica, reconocían que «le mariage est souvent utile», pero «moins en raison du rapprochement sexuel en lui-même que par le changement de régime et d'idées qu'il entraîne» (756 a).

$Y$ es que por esas fechas Jean-Martin Charcot había dado a conocer sus ideas al respecto. En sus Leçons sur les maladies du système nerveux, faites à la Salpêtrière, publicadas en partes entre 1872 y 1873, afirma estar lejos de creer que la lubricidad esté siempre en juego en la histeria («je suis loin de croire que la lubricité soit toujours en jeu dans l'hystérie»), y si bien no se muestra partidario de las teorías antiguas, distingue una forma de la enfermedad en que los órganos genitales desempeñan un papel fundamental, y es la que llama histeria "ovarienne ou ovarique» (266) ${ }^{31}$.

En España la polémica apenas existe, porque los pocos médicos, frenólogos y ginecólogos para ser más exactos, parecen decantarse más por la teoría clásica, aunque siempre con excepciones. Así, Pedro Felipe Monlau, en su libro Higiene del matrimonio, publicado por primera vez en 1853 y del que salieron un buen número de ediciones posteriores, corregidas y ampliadas, afirmaba que «en la matriz retumban indefectiblemente todas las afecciones físicas y morales de la mujer», y refrendaba semejante teoría, uterina, y no cerebral, traduciendo la sentencia hipocrática, «el útero hace que la mujer sea lo que es» ${ }^{32}$, también atribuida a Juan Bautista Val Helmont, según recuerdan Marc-Hector Landouzy y Jean-Louis Brachet, uno para confirmarla, el otro, en cambio, para refutarla («ce n'est pas seulement par l'uterus que la femme est ce qu'elle est») ${ }^{33}$. Monlau comparte la teoría uterina, al igual que una de

31. He citado por la edición original de 1872-1873, pero el fragmento también puede leerse en la antología preparada por E. Trillat, L'hystérie, pp. 26-27.

32. La referencia la tomo de Asunción Doménech Montagut, Medicina y enfermedad, p. 187, y Género y enfermedad mental, p. 61, n. 140, y de Bridget Alharaca, art. cit., pp. 5253. La cita en latín también la saca a colación E. Bouchut y Armand Després, Dictionnaire de médecine..., p. 755a: «l'hystérie semble être l'effet réflexe des troubles fonctionnels ou des maladies de l'utérus et de ses annexes, ce qui explique pourquoi on ne l'observe que chez la femme: Propter uterum mulier est id quod est".

33. Landouzy la atribuye a Hipócrates y después a Van Helmont (p. 227), mientras que Brachet ofrece como paternidad única la del médico belga (p. 63). 
sus posibles fuentes, la obra de Auguste Dubay, Hygiène... du mariage, y en un artículo publicado en la revista La Guirnalda, el 20 de agosto de 1882, deja claro que es la histeria una enfermedad inherente a la mujer:

Por último, existe encarnada en la organización de la mujer la condición histérica, que es normal en ella; es resultado del alto desarrollo de lo emocional en su sistema nervioso, y ha existido desde que la mujer fue mujer, en todos los grados de civilización y en todas sus variedades físicas y mentales. Está en continuo peligro de estallar desenfrenada e inesperadamente en paroxismos producidos por el menor acontecimiento... Esta condición histérica puede compararse a un paquete de dinamita: inofensivo mientras sus partículas están en equilibrio, terrible cuando se conmueve ${ }^{34}$.

En 1875, el ginecólogo Ángel Pulido, en la sesión de apertura del tercer año de la Sociedad Ginecológica, pronuncia un discurso sobre «La naturaleza y el tratamiento de la histeria», en que sigue localizando la enfermedad en "el aparato generador interno de la mujer». Un poco antes, el frenólogo barcelonés Juan Giné y Partagás, en su Tratado Teórico-Práctico de FrenoPatología (Barcelona, 1871), sin embargo, sitúa su origen en el «tálamo óptico", y bastante después, en 1889, el doctor Esquerro considera la histeria como enfermedad mental, aunque sigue apoyando las ideas de Pulido ${ }^{35}$.

\section{LOS PERSONAJES DE LA LITERATURA}

Las vidas de algunos personajes femeninos estudiados hasta aquí tienen el denominador común de la continencia. Madame Gervaisais, con treinta y siete años, es una mujer viuda que no se relaciona, desde el punto de vista sexual, con ningún hombre, y en sus años de matrimonio tampoco satisfizo sus necesidades físicas ni morales. Marthe Rougon, a sus treinta y siete años, está casada con un hombre con quien en la actualidad no tiene ningún tipo de relación sexual, y a cuya vera lleva una vida aburrida y sin emociones. Doña Paulina Porreño, a sus treinta y dos años, sigue soltera, porque, en edad núbil, había rechazado la posibilidad del matrimonio. Después de conocer a Lázaro, concibe la idea de una vida conyugal que hasta entonces nunca había tenido en cuenta.

34. El pasaje aparece citado por Bridget A. Aldaraca, El ángel del hogar: Galdós y la ideología de la domesticidad en España, Visor, Madrid, 1992, p. 57.

35. Para el panorama de la enfermedad en España, véase Bridget A. Aldaraca, art. cit. 
Los autores de esos personajes femeninos podían conocer las ideas sobre la histeria que hemos resumido en el capítulo anterior, pero no sabemos por qué teoría se habrían decantado. Para empezar, ninguno de ellos llama a la enfermedad por su nombre, y todos insisten en tratarla como una patología de tipo nervioso, quizá, y sólo quizá, como prueba de su resistencia a aceptar las teorías uterinas sobre la enfermedad (porque histeria en griego significaba 'útero').

Flaubert, por ejemplo, en su correspondencia con Georges Sand, de enero de 1867, llega a decir que las damas bellas le han ocupado siempre el espíritu, pero que nunca le han hecho perder el tiempo, y en ese sentido se presenta como un anacoreta a la vez que se define como un viejo histérico, convencido de que la enfermedad es común a hombres y mujeres, y reconoce que para la composición de Salambô, que había comenzado el 1 de septiembre de 1857, se había documentado sobre el tema:

J'ai des battements de cour pour rien, chose incompréhensible, du reste, dans un vieil hystérique comme moi. Car je maintiens que les hommes sont hystériques comme les fermmes et que j'en suis un. Quand j'ai fait Salambô j’ai lu sur cette matière-là «les meilleurs auteurs» et j'ai reconnu tous mes symptômes ${ }^{36}$.

En otra carta dirigida al mismo destinatario, el 1 de mayo de 1874, le confiesa su propósito de huir al campo, a las montañas suizas, para airearse y descongestionarse, siguiendo los consejos del doctor Hardy, quien lo había llamado «femme hystérique».

Dans une quinzaine, je mien retourne vers ma maison des champs. Au mois de juillet, jirrai me décongestionner sur le haut d'une montagne, en Suisse, obeíissant au conseil du docteur Hardy, lequel m’appelle «une femme hystérique», mot que je trouve profond ${ }^{37}$.

En su artículo sobre Madame Bovary, publicado en la revista «l'Artiste» el 18 de octubre de 1857, Baudelaire no puede menos que invocar el nombre de la histeria, porque cree que Emma ha sucumbido de manera inequívoca a esa enfermedad, de la que también ofrece algunos de sus síntomas, sin duda los más conocidos y representativos:

36. Flaubert, Oeuvres complètes. Correspondance, 6e série, París, 1929, p. 268-269.

37. Correspondance, $7^{\mathrm{e}}$ série, p. 134. 
L'hystérie! Pourquoi ce mystère physiologique ne ferait-il pas le fond et le tuf d'une ouvre littéraire, ce mystère que l'Académie de médecine n'a pas encore résolu, et qui, s'exprimant dans les femmes par la sensation d'une boule ascendante et asphyxiante (je ne parle que du symptôme principal), se traduit chez les hommes nerveux par toutes les impuissances et aussi par l'aptitude à tous les excès? ? $^{38}$

En una carta a Zola, del 3 de junio de 1874, Flaubert le hace saber que ha leído La conquête de Plassans y que le ha gustado mucho; al hablar de Marthe destaca sus estados histéricos, y señala las páginas en que descubre un cambio en el carácter de la mujer de Mouret:

Quant à elle (Marthe), je ne saurais vous dire combien elle me semble réussie, et l'art que je trouve au développement de son caractère, plutôt de sa maladie. J'ai surtout remarqué les pages 194, 215 et 227, 261, 264, 267. Son état hystérique, son aveu final ( $p 350$ et sq) est une merveille ${ }^{39}$.

También había dedicado elogios a Madame Gervaisais, en carta a la Princesa Matilde, de febrero de 1869, pero sin entrar en detalles sobre la protagonista:

Que pensez-vous de Madame Gervaisais? Entre nous, je n'ose pas vous dire que je trouve ce livre très remarquable, car vous avez le gồt difficile ${ }^{40}$.

Por lo que respecta a Galdós, es difícil saber qué teoría apoyaba en la década de lo setenta, si la cerebral o la uterina. Sus personajes ponen de manifiesto una castidad para la que no parecen haber nacido. La menor de las Porreńo sigue casta a los treinta y pico ańos, y sus problemas se habrían solucionado de haberse casado con Lázaro. La propia implicada, en la última conversación con Lázaro, se da cuenta que toda su vida anterior ha sido una farsa y contempla el futuro desde la perspectiva de la paz y la tranquilidad del matrimonio, pensando, sin lugar a ninguna duda, en poder contraerlo con el joven aragonés:

38. El artículo de Baudelaire puede leerse en la siguiente página de internet: www. bmilisieux.com/litterature/ baudelaire/ bovary.

39. Correspondance, $7^{\mathrm{e}}$ série, p. 142.

40. Correspondance, $6^{\mathrm{e}}$ série, p. 15 
Pienso que estoy destinada a largos días de paz y felicidad, de que disfrutará alguien conmigo... ¿Qué estado puede igualarse por su dignidad y nobleza al estado de esposa, de cuya solicitud penden tantas felicidades, la vida de tantos seres? (376).

Se imagina sublimando las «flaquezas humanas» a través de «los lazos de la familia», en cuyo desempeño supone mil dificultades, que no sólo se superan con «el mutuo amor», sino por otros medios que no llega a especificar, y abraza la idea de entregar toda su fortuna, que acaba de descubrir en el mueble del reclinatorio, para satisfacer las ambiciones de su futuro marido, y para afrontar las necesidades de esa vida en común que ya había sońado junto a él. Paulina sabía que la solución a sus males pasaba por el matrimonio con el hombre del que se había enamorado, y no sólo para satisfacer esas flaquezas que se han manifestado de forma alarmante después de conocerlo.

\section{CONCLUSIÓN}

Galdós sólo emplea la palabra histerismo en novelas ya tardías, como Nazarin (1895) o Torquemada y san Pedro (1895) ${ }^{41}$, pero ya en sus primeras novelas parece aludir a la enfermedad, aunque sin llamarla por su nombre, sino usando el de otras patologías asociadas a ella, como catalepsia o congestión cerebral. Se inventa un personaje, en La Fontana de oro, que por su excesiva devoción padece ataques de delirio que la dejan como muerta, sin sentido alguno. Para perfilar las señas de identidad de ese personaje, el de doña Paulina, se ha podido basar en el de Madame Gervaisais de la novela homónima de los hermanos Goncourt, pero también en los numerosos tratados, escritos en francés, sobre la catalepsia y la histeria, que también influyen de manera decisiva en la conformación del personaje de Marthe

41. En la primera de las dos obras, es una prostituta, Beatriz, quien padece la enfermedad (ed. Gregorio Torres Negrera, Castalia, Madrid, 2001, p. 191), y en la segunda, la marquesa Fidela, casada con el usurero Torquemada, con quien tiene un hijo retrasado, y en ese sentido el personaje en cuestión presenta afinidades con Madame Gervaisais y Marthe Rougon (Alianza Editorial, Madrid, 2004, p. 537). En Torquemada en la Cruz, Justa, la mujer de José Donoso, padece numerosas enfermedades imaginarias, entre las que ella misma cita el «bolo histérico» (ed. cit., 168). El Dictionnaire des sciences médicales distingue entre "histerismo» e "histeria», al considerar la primera variedad, admitida ya por algunos autores, como una forma atenuada de la segunda que se pone de manifiesto «avant l'âge de la puberté» (242). 
Rougon creado por Zola en La conquête de Plassans, o en el de Madame Bovary en la novela homónima de Flaubert.

Nuestro novelista intenta establecer analogías entre el personaje de Paulina y el histórico de santa Teresa, porque conocía los problemas de salud que la abulense había reconocido en su Libro de la vida; podía haber achacado esos problemas de salud que padece doña Paulina a su excesiva dedicación a la religión, que para Paul Briquet, por ejemplo, podía ser una de las causas de la histeria. Galdós, sin embargo, no acaba de dejar claro si la enfermedad de la menor de las Porreño se debe a la castidad, o a esa excesiva devoción a la que se había entregado desde la niñez por haberla pasado en un convento. El autor canario, en cambio, no parece dudar de los beneficios que habría supuesto para Paulina el matrimonio con Lázaro, porque, al frustrarse semejante empeño, la deja ingresada en un convento, con mayores problemas de salud que antes. Galdós podría haber optado por una postura más ecléctica, la misma que defendía Charcot poco antes de la publicación de La familia de León Roch: la lujuria no siempre es determinante de la histeria, pero a veces puede influir a que lo sea. 